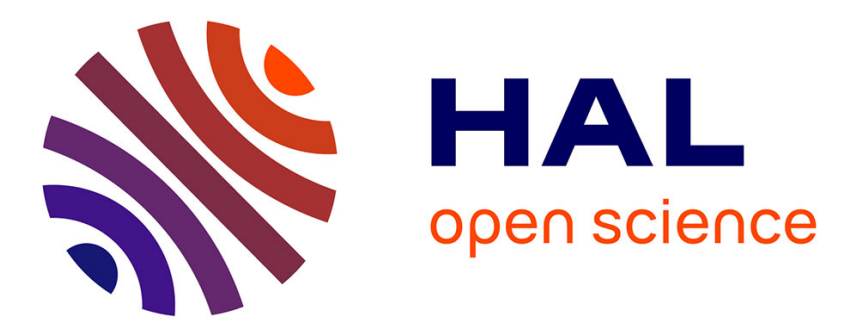

\title{
Linking objective and subjective modeling in engineering design through arc-elastic dominance
}

\author{
Patrick Sebastian, Yann Ledoux, Arnaud Collignan, Jérôme Pailhes
}

\section{To cite this version:}

Patrick Sebastian, Yann Ledoux, Arnaud Collignan, Jérôme Pailhes. Linking objective and subjective modeling in engineering design through arc-elastic dominance. Expert Systems with Applications, 2012, 39 (9), pp.7743-7756. 10.1016/j.eswa.2012.01.079 . hal-01020737

\section{HAL Id: hal-01020737 https://hal.science/hal-01020737}

Submitted on 8 Jul 2014

HAL is a multi-disciplinary open access archive for the deposit and dissemination of scientific research documents, whether they are published or not. The documents may come from teaching and research institutions in France or abroad, or from public or private research centers.
L'archive ouverte pluridisciplinaire HAL, est destinée au dépôt et à la diffusion de documents scientifiques de niveau recherche, publiés ou non, émanant des établissements d'enseignement et de recherche français ou étrangers, des laboratoires publics ou privés. 


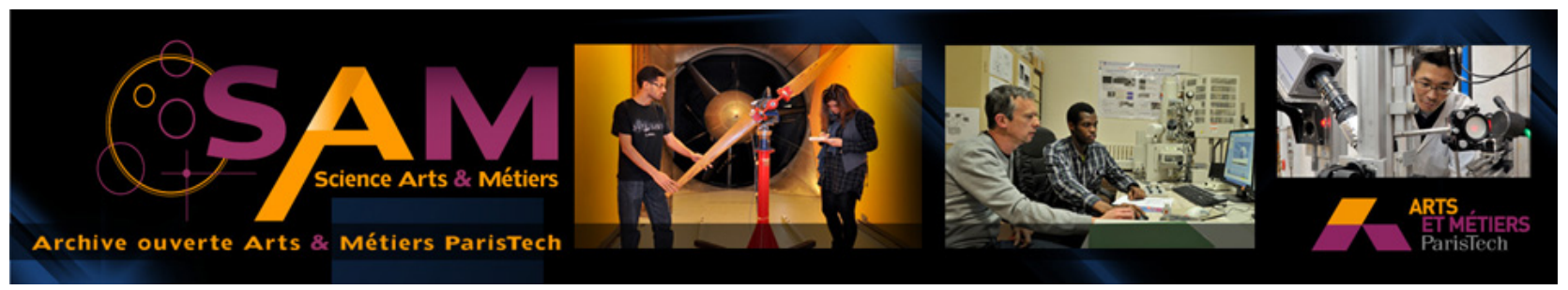

Science Arts \& Métiers (SAM)

is an open access repository that collects the work of Arts et Métiers ParisTech researchers and makes it freely available over the web where possible.

This is an author-deposited version published in: http://sam.ensam.eu

Handle ID: .http://hdl.handle.net/10985/8330

\section{To cite this version :}

Patrick SEBASTIAN, Yann LEDOUX, A COLLIGNAN, Jérôme PAILHE - Linking objective and subjective modeling in engineering design through arc-elastic dominance - Expert Systems with Applications - Vol. 39, n`9, p.7743-7756 - 2012 


\title{
Linking objective and subjective modeling in engineering design through arc-elastic dominance
}

\author{
P. Sebastian ${ }^{\mathrm{a}, *}$, Y. Ledoux $^{\mathrm{a}}$, A. Collignan ${ }^{\mathrm{a}}$, J. Pailhes ${ }^{\mathrm{b}}$ \\ a Université de Bordeaux, Laboratoire TREFLE, UMR CNRS 8508, Esplanade des Arts et Métiers, 33405 Talence Cedex, France \\ ${ }^{\mathrm{b}}$ Arts et Métiers ParisTech, Laboratoire TREFLE, UMR CNRS 8508, Esplanade des Arts et Métiers, 33405 Talence Cedex, France
}

Keywords:

Arc-elasticity

Multiobjective optimization

Multi-criteria decision analysis

Engineering design

Geothermal air conditioning

\begin{abstract}
A B S T R A C T
Engineering design in mechanics is a complex activity taking into account both objective modeling processes derived from physical analysis and designers' subjective reasoning. This paper introduces arc-elastic dominance as a suitable concept for ranking design solutions according to a combination of objective and subjective models. Objective models lead to the aggregation of information derived from physics, economics or eco-environmental analysis into a performance indicator. Subjective models result in a confidence indicator for the solutions' feasibility. Arc-elastic dominant design solutions achieve an optimal compromise between gain in performance and degradation in confidence. Due to the definition of arcelasticity, this compromise value is expressive and easy for designers to interpret despite the difference in the nature of the objective and subjective models. From the investigation of arc-elasticity mathematical properties, a filtering algorithm of Pareto-efficient solutions is proposed and illustrated through a design knowledge modeling framework. This framework notably takes into account Harrington's desirability functions and Derringer's aggregation method. It is carried out through the re-design of a geothermal air conditioning system.
\end{abstract}

\section{Introduction}

Bantayan and Bishop have proposed the term physico-subjective modeling (Bantayan \& Bishop, 1998) for modeling procedures combining both objective models (chiefly related to physical phenomena analysis) and subjective models in a single paradigm. Design processes in industrial design departments must simultaneously take into account data resulting from complex phenomena analysis and subjective or incomplete information. Like Wang (2001), we believe that most research assumes a perfect compensation between subjective and objective models, which means that it should always be possible to make a trade-off among subjective and objective criteria. The incomparability, in practice, between alternatives is generally completely ignored.

The purpose of engineering design problem modeling (EDPM) is to analyse design problems into elements or principles and translate them into mathematical models related to computing environments. If necessary, these models must be related to operators, algorithms or particular methods to be solved efficiently. EDPM deals with the cognitive aspects of engineering design. Designers always work in a bounded rationality context (Simon, 1982) because they have to deal with many sources of variability and epistemic uncertainty (Ben-Haim, 2000). Due to the complexity and

\footnotetext{
* Corresponding author. Tel.: +33 (0) 556845 414; fax: +33 (0) 556845436 .

E-mail address: Patrick.sebastian@trefle.u-bordeaux.fr (P. Sebastian).
}

difficulties inherent in their activities, designers are always coping with a lack of information and knowledge, limitations of delays and means, multiplicity and distribution of resources. However, as they are the first actors intervening in the life cycle of industrial products (Pahl \& Beitz, 1996), their decisions determine the feasibility of industrial products and highly influence future performances (Berliner \& Brimson, 1988). As a result, EDPM must rise to the challenge of modeling cognitive aspects of designers' reasoning to produce optimal design solutions from the points of view both of the physical knowledge carried out through the design process and designers' interpretations.

Much scientific effort has been put into multi-criteria decision analysis (MCDA) in developing fuzzy logic-based or rough set-based methods resulting in outranking preference models (Greco, Matarazzo, \& Słowiński, 2001; Perny, 1998), namely models expressing preference/indifference relations between pairs of solutions. These approaches are focused on fuzziness of subjective knowledge and aim at translating fuzzy knowledge into mathematical rules suitable for integrating into the digital processing loops of design departments. However, since knowledge taken into account in these rules remains subjective, designers may be reluctant to integrate physical behavior models based on an impersonal comprehension of the world, with such uncertain and subjective models. The subjective/objective antagonism remains an open problem in engineering design because there is a lack of systematic methods to support designers in the process of organizing and 
structuring different levels of knowledge through the design process. Multi-criteria decision analysis tools and methods must be related to an EDPM framework to resolve this antagonism.

This issue can be tackled by taking a systematic approach to the hierarchy of decisional criteria of design problems. Analytic Hierarchy Processes (AHP) have been extensively studied to tackle this difficulty and applied to a wide range of scientific fields such as economics, medical sciences and engineering (Nepal, Yadav, \& Murat, 2010; Saaty, 2001). Using this method we propose to build dominance indicators by defining partial order relations from the observation variables of models. Partial order relations are based on pairwise comparisons performed between the values of the indicators, leading to the parameterization of weighting parameter matrices. From linguistic interpretations related to numerical scales, deciders must appreciate the comparison between pairs of selection criteria. In this paper, a similar approach dedicated to engineering design modeling is proposed aimed at structuring knowledge from the definition of design variables to a global dominance indicator called arc-elasticity. From this dominance indicator designers are able to rank design solutions using two preference indicators related to objective and subjective models. Objective physical or economical models and designers' subjective reasoning models are distinct but they result from equivalent processes of observation, interpretation and aggregation. It must be noted that, in what follows, an engineering design model is defined as a sequence of observation, interpretation and aggregation models. A model is regarded as being objective once the observation model contributing to its definition is based on physical phenomena or economic analysis. Interpretation and aggregation functions are at least partially related to subjective knowledge.

Solution dominance is computed from an algorithm based on the calculation of an arc-elasticity value, namely a ratio of nondimensional deviations defined according to the gain in value of one preference indicator and the degradation in the other. Originally, the concept of arc-elasticity was introduced through the works of Cournot (1838) and Marshall (1920) and was applied to micro-economic analysis. Marshall investigated the adequacy between the demand relating to a product and its price (price elasticity of demand) by comparing two distinct states 1 and 2 of a product. Elasticity $\varepsilon_{1,2}$ is defined through demands $\left(x_{1}\right.$ and $\left.x_{2}\right)$ and prices $\left(y_{1}\right.$ and $\left.y_{2}\right)$ related to the two states:

$\delta \bar{x}=\frac{x_{2}-x_{1}}{\left(x_{2}+x_{1}\right) / 2}, \quad \delta \bar{y}=\frac{y_{2}-y_{1}}{\left(y_{2}+y_{1}\right) / 2}, \quad \varepsilon_{1,2}=\frac{\delta \bar{y}}{\delta \bar{x}}$

Elasticity concept has received attention in many application domains concerned with the design of complex systems such as transportation networks (Beuthe, Jourquin, Geerts, \& Koul à Ndjang'Ha, 2001; Odeck \& Brathen, 2008), computer networks (Drèze \& Zufryden, 2004) or mechanical systems (Collignan, Sébastian, Pailhès, \& Ledoux, 2011). However, in engineering design, designers are more directly concerned with the concept of performance than the concept of demand. Throughout the design process, product demand and costs are both taken into account through marketing requirements, which form part of the design requirement documents, and, consequently, result from the satisfaction of performance constraints. Demand and costs are perceived as a consequence of the performance of the system being designed. Therefore, in this paper, we propose to define elasticity as a ratio between performance and confidence deviations related to a pair of design solutions.

Elasticity is a ratio of non-dimensional quality indicators. As a ratio of non-dimensional variables, it is expressive and may be easily interpreted as a beneficial (or detrimental) variation in one indicator of a problem resulting in a detrimental (or beneficial) variation in the other compensatory indicator. By relating solution couples to their arc elasticity, any kind of transformation of one solution into the other can be interpreted as detrimental, neutral or beneficial. Due to the high interpretability of arc elasticity and from designers' confidence appreciation of subjective models, decision-making is supported by a numerical value equivalent to a pairwise comparison between the "fair" and "partial" models. This interpretability is reinforced by the similarity in the modeling processes of the two types of models, which, nevertheless, remain independent.

\section{Elasticity and filtering algorithm}

In this paragraph, we define the mathematical framework of a design solution filtering method based on arc-elastic dominance. This approach aims at screening solutions, starting from a reference solution, and is based on the calculation of the arc-elasticity of couples of solutions. Arc-elasticity is related to a partial order relation and we propose an algorithm resulting in solutions combining Pareto-efficiency properties with properties derived from the partial order relation.

\subsection{Variables and models}

Let us consider a candidate solution (design alternative) to resolving a problem, which is defined from vector $X$ containing each of the $m$ variables denoted $x_{j}$. These variables are identified as design variables when they are considered through a product design process and correspond to the evaluation of the characteristics of the solution. From the more general point of view of decision theory, design variables are identified as decision variables. Observation variables $Y$ are computed from design variables $X$ through an analytical model taking into account physical, economic, environmental or manufacturing knowledge. The global performance of the candidate solution is derived from the value of response variables observed in the model. The $n$ response variables $y_{i}$ are assembled in vector $Y$. Therefore,

$X=\left[x_{1}, x_{2}, \ldots, x_{m}\right]^{T}, \quad Y=\left[y_{1}, y_{2}, \ldots, y_{n}\right]^{T}$

Where,

$X \in \Omega$

$\Omega$ is the value domain of the design variables, which defines the design solution search space. $Y$ and $X$ variables are linked through the model as:

$Y=\mu(X)$

where $\mu$ is decomposed into $\mathrm{n}$ elementary functions:

$\forall i \in\{1, \ldots, n\}, y_{i}=\mu_{i}(X)$

It is also supposed that every solution is related to two different preference functions noted $\varphi_{u}$ and $\varphi_{v}$ corresponding to positive values, which must be maximized. In the following, $\varphi_{u}$ and $\varphi_{v}$ will be regarded as confidence and performance indicators. The preference function is relative to both a reference solution $X_{s}$ and a candidate solution $X$. The preference value $u$ of the candidate solution is computed from the preference function $\varphi_{u}$ :

$u=\varphi_{u}\left(X, X_{s}\right)$

More to the point, we assume that the reference solution itself is the solution of maximal confidence and is related to the maximal preference $\mathrm{u}$, namely:

$\forall X: \varphi_{u}\left(X, X_{s}\right) \leq \varphi_{u}\left(X_{s}, X_{s}\right)$

The other preference function depends on the response variables and, from these variables, it is related to the design variables from the preference function $\varphi_{v}$ :

$v=\varphi_{v}(X)$ 


\subsection{Order relation between solutions}

Let us now consider a population of solutions identified through their design variables $X_{i}$. These candidate design solutions are observed through the two preference indicators $u$ and $v$. One particular design solution $X_{s}$ (reference solution) is selected among the population at each step of an iterative process. Fig. 1 shows the population of solutions $X_{i}$ and highlights the Pareto-efficient (Pareto-dominant) solutions of the set. Pareto-efficient solutions $X_{i}$ correspond to solutions which are better than any other solution $X_{j}$ of the set regarding the value of at least one of the preferences $u$ or $v$. $X_{i}$ is a Pareto dominant solution of the set if and only if (where symbol " $\vee$ " stands for "or"):

$$
\forall j:\left(u_{i} \geq u_{j}\right) \vee\left(v_{i} \geq v_{j}\right)
$$

The set of Pareto dominant solutions is useful in engineering since designers can perform tradeoffs within this set, rather than considering the full range of every solution that satisfies the requirements of a design problem. These solutions are regarded as more efficient than every non-dominant solution according to at least one criterion. For this reason, the solution filtering method proposed in this paper aims at screening Pareto-efficient solutions and, consequently, results in solutions combining Pareto-efficiency properties and other assets derived from optimal elasticity.

Solution filtering based on arc-elasticity is related to an equivalence hypothesis between the preference indicators $u$ and $v$. Let us consider a selection process where, starting from a reference solution $X_{s}$, a new solution must be selected among two points $X_{q}$ and $X_{r}$ (see Fig. 1) from the Pareto-efficient solution set. $X_{q}, X_{r}$ and $X_{s}$ are ranked according to preferences $u$ and $v$ as (where symbol “ $\wedge$ " stands for "and"):

$\left\{X_{r}, X_{q}, X_{s}:\left(u_{r} \leq u_{q} \leq u_{s}\right) \wedge\left(v_{r} \geq v_{q} \geq v_{s}\right)\right\}$

We now consider the case where, compared to $X_{s}, X_{q}$ and $X_{r}$ are of similar value according to $u$, but $X_{r}$ is much preferable to $X_{q}$ according to $v$ :

$\left(u_{r}-u_{q}\right)<<\left(u_{q}-u_{s}\right)$

whereas,

$\left(v_{r}-v_{q}\right)>>\left(v_{q}-v_{s}\right)$

If we assume that a small increase in the reduction of preference $u$ (starting from $X_{s}$ and selecting $X_{r}$ rather than $X_{q}$ ) is justified by a high increase in preference $v$, then this allows us to globally prefer solution " $r$ " to solution " $q$ ". This is expressed by a partial order relation relating points $X_{q}$ and $X_{r}$ :

$X_{q} \prec X_{r}$

On the contrary,

$\left\{\begin{array}{l}\left(u_{r}-u_{q}\right)>>\left(u_{q}-u_{s}\right) \\ \left(v_{r}-v_{q}\right)<<\left(v_{q}-v_{s}\right)\end{array} \Longleftrightarrow X_{q} \succ X_{r}\right.$

and in any other situation that agrees with Eq. (10):

$X_{q} \cong X_{r}$

Such a relation of order makes sense provided that variables $u$ and $v$ can be compared, which means that variations in $u$ and $v$ are detrimental or favorable in equivalent manner to the selection of the solution. This point will be discussed and developed in Section 4 of the article.

Elasticity of preferences $u$ and $v$ is defined as a non-dimensional ratio between variations in $u$ and $v$. Therefore, we define elasticity relative to preferences $u$ and $v$ as:

$\varepsilon_{j, i}=\frac{v_{j}-v_{i}}{v_{j}+v_{i}} \cdot \frac{u_{j}+u_{i}}{u_{j}-u_{i}}$

The definition of elasticity can be used to rationalize the partial order relation, namely to translate the relation of order into a numerical relation. The following relations can be easily demonstrated:

$\left\{\begin{array}{l}X_{q} \succ X_{r} \Rightarrow-\varepsilon_{s, q}>-\varepsilon_{s, r} \\ X_{q} \cong X_{r} \Rightarrow-\varepsilon_{s, q} \cong-\varepsilon_{s, r} \\ X_{q} \prec X_{r} \Rightarrow-\varepsilon_{s, q}<-\varepsilon_{s, r}\end{array}\right.$

It must be noted that we consider negative values of arc-elasticity since it is a ratio between gain (positive) and degradation (negative) of preference indicators. Such a ratio of indicators results in a dominance indicator, which has to be maximized.

\subsection{Elasticity as a dominance indicator}

We propose to use elasticity as a global dominance indicator to select design solutions in the course of an iterative optimization process. Through elasticity optimization, it is assumed that a solution is globally preferable if:
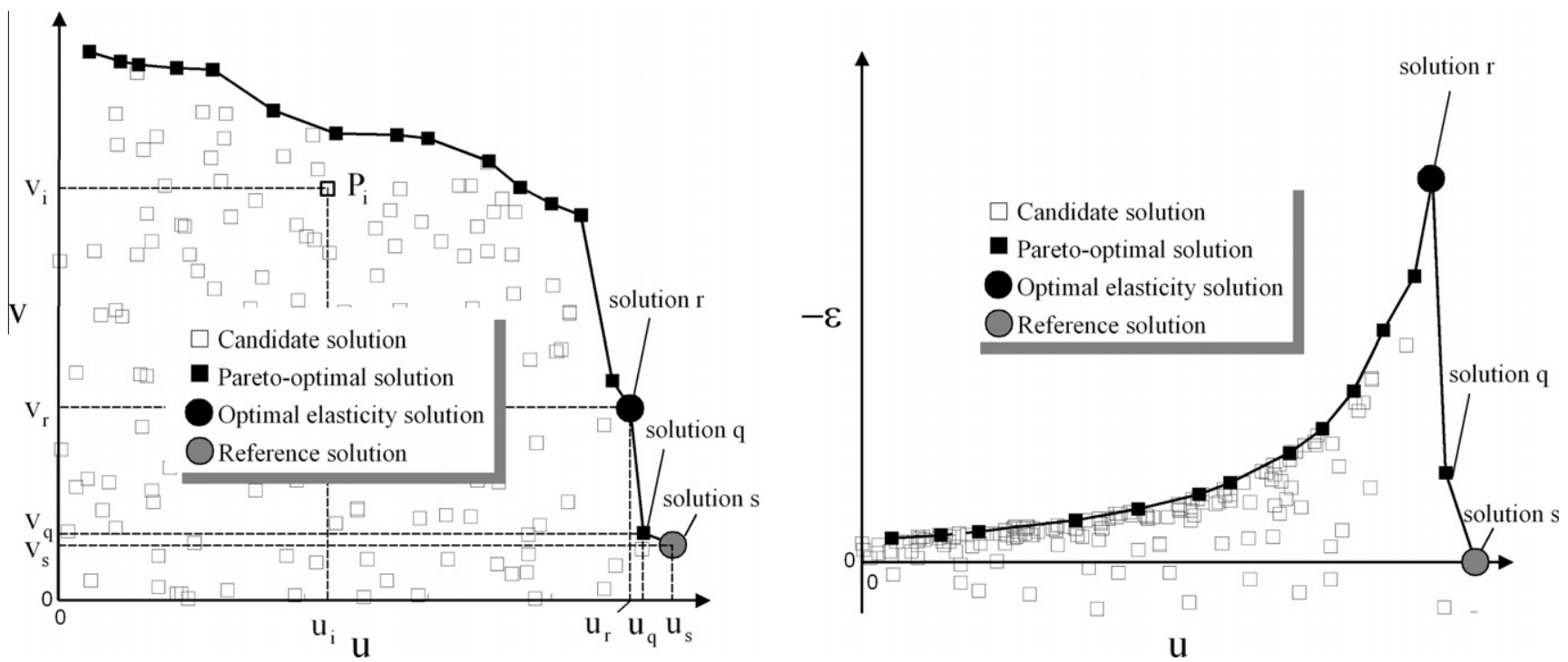

Fig. 1. Indicators $u$ and $v$ and elasticity curve of a population of solutions. 
- it is Pareto-efficient,

- there is no other solution which is both close to it regarding one preference indicator ( $u$ or $v$ ) and much more preferable regarding the other preference indicator $(v$ or $u$ ).

Once the reference solution $X_{s}$ belongs to the Pareto-efficient solution set, the optimal elasticity solutions $X_{i}$ maximizing the value of $-\varepsilon_{i, s}$ also belong to this Pareto set. This can be demonstrated by investigating the iso-elasticity curves derived from Eq. (16):

$v_{i}=v_{s} \cdot\left(\frac{1-\varepsilon_{i, s} \cdot\left(u_{i}+u_{s}\right) /\left(u_{i}-u_{s}\right)}{1+\varepsilon_{i, s} \cdot\left(u_{i}+u_{s}\right) /\left(u_{i}-u_{s}\right)}\right)$

which is equivalent to a function $v(u)$ parameterized by the elasticity $\varepsilon$ and the preferences $u_{s}$ and $v_{s}$ of the solution $X_{s}$ (see Fig. 2), with:

$v(u):=v_{s} \cdot\left(\frac{(1-\varepsilon) \cdot u-(1+\varepsilon) \cdot u_{s}}{(1+\varepsilon) \cdot u-(1-\varepsilon) \cdot u_{s}}\right)$

In the following, we are interested in negative elasticity values since Pareto-efficient solutions cannot be improved according to both $u$ and $v$, and, consequently, are related to negative elasticities. Isoelasticity functions are monotonous functions and for negative values of elasticity, we have:

$\left(-\varepsilon_{i, s}>0\right) \wedge\left(u_{i}<u_{j}\right) \wedge\left(v_{i}<v_{j}\right) \Rightarrow\left(-\varepsilon_{i, s}<-\varepsilon_{j, s}\right)$

Therefore, if at least one solution is related to a negative value of elasticity, a solution $X_{i}$ maximizing the value of the elasticity belongs to the Pareto-efficient set. Indeed, if it is not, at least one other solution $X_{j}$ exists with a higher value than both $u$ and $v$ (see Eq. (9)), which implies, from Eq. (20), that the efficiency of solution $X_{j}$ is higher than the efficiency of solution $X_{i}$. From this, we can derive that $X_{i}$ does not match the maximal value of $-\varepsilon_{i, s}$.

\subsection{Filtering algorithm}

From this property, an algorithm (illustrated in Fig. 3) is proposed to filter Pareto-efficient solutions through the concept of arc-elastic dominance (arc-elasticity optimality). Starting from a Pareto-efficient solution set defined through design variable vectors $X_{i}$ and the index $s(1)$ of an initial reference solution belonging to this population, the preference values $u$ and $v$ are computed for every solution of the set. The elasticity value of every solution is then computed to determine the solution related to optimal elasticity (maximal value of $-\varepsilon$ ). If this arc-elasticity value is lower

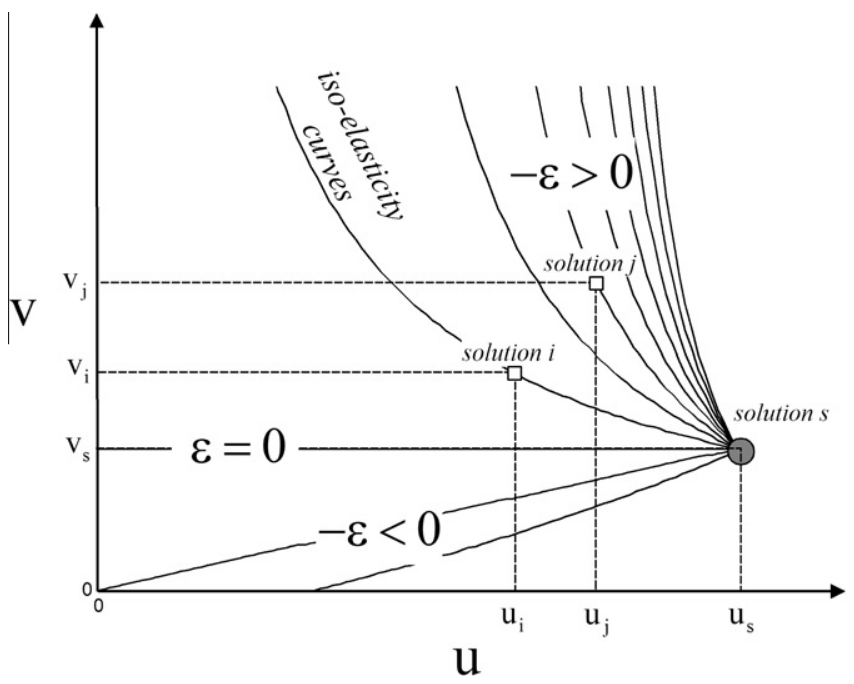

Fig. 2. Iso-elasticity curves. than an objective arc-elasticity, then this solution belongs to the Pareto set and is used as a new reference value to iterate the process. The preference values are recomputed and the algorithm is iterated until the elasticity becomes positive. The algorithm results in a list of Pareto-efficient solutions and their corresponding arc elasticity values; the solution number $k+1$ of the list is related to an elasticity value $\varepsilon_{s(k+1), s(k)}$ qualifying the ratio between the percentage in the gain of $v$ and the percentage in the loss of $u$ relative to the solution number $k$. As a ratio between a gain (benefit) and a loss (cost), the absolute value of elasticities can be interpreted as a quality index related to the transformation of a solution into another.

It must be noted that optimal elasticity solutions are dissimilar to solutions belonging to the convex polytope distinctive of the solution set. In Fig. 3, point $P$ belongs to the convex polytope frontier but is not a solution of optimal elasticity, whereas point $Q$ does not belong to the convex polytope frontier but is a solution of optimal elasticity.

\subsection{Filtering algorithm interpretation}

Fig. 4 illustrates the interpretation of arc-elasticity values. Highly elastic solutions correspond to highly negative values of the elasticity and, consequently, to high gains in preference $v$ related to low losses in preference $u$. Elastic solutions are of good quality and must be given priority when considered throughout the process of selecting new design solutions. Unit elastic solutions or relatively inelastic solutions are less interesting since they correspond to equivalent or higher degradations of preference $u$.

In the following, we illustrate the filtering algorithm through a multi-objective design approach, where preferences $u$ and $v$, respectively correspond to confidence and performance preferences. Confidence relates to a pre-existing design configuration regarded as preferable because it has already been developed and tested. Performance is supported by analytical models derived from physical and economical investigations. The filtering method aims at finding a good compromise between knowledge derived from expertise (subjective) and knowledge derived from physical analysis (objective).

\section{Design modeling strategy}

\subsection{Scientific background}

In the field of decision support in engineering design, problems are formalized through criteria that evaluate design alternatives according to several points of view. Design problem formulation results in multi-criteria decision analysis (MCDA) problems. The main difficulties concern the translation of the basic information resulting from modeling into relevant criteria (observation, interpretation) and the aggregation of these criteria into an appropriate recommendation or prescription (aggregation). Due to the antagonistic nature of the criteria, there is often no design solution preferable to every other alternative.

An examination of scientific literature shows that the statement of preference in engineering design is addressed by developing three types of approach (Augusto, Rabeau, Dépincé, \& Bennis, 2006). Designers' preferences are processed by formulating them inside the model of the design problem (a priori statement), through interactions during the numerical solving phases (interactive statement) or by selecting solutions a posteriori (a posteriori statement) that take these preferences into account. A priori statements assume that designers are able to translate their knowledge through rational rules and mathematical relations, whereas, in essence, some preferences are difficult to express. Therefore, soft 


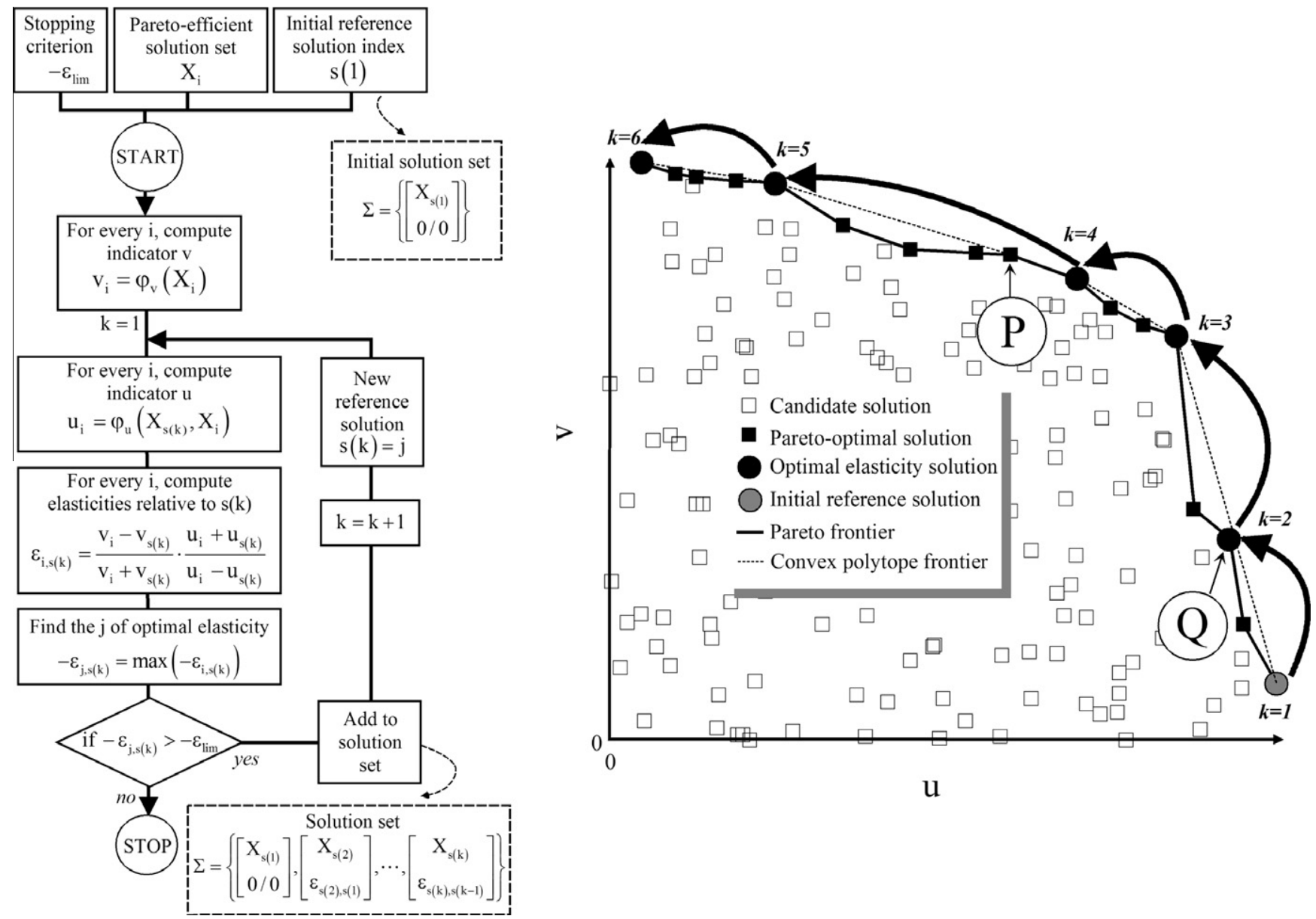

Fig. 3. Filtering algorithm and illustration with $\varepsilon_{\lim }=0$.

computing and fuzzy logic is receiving considerable attention for modeling preferences (Antonsson \& Sebastian, 2005; Hung, Julian, Chien, \& Jin, 2010; Saridakis \& Dentsoras, 2008) due to the intrinsic fuzziness in designers' preferences. Similar approaches consist in using desirability functions (Harrington, 1965) to translate design requirements and designers' preferences into relaxed constraints. Starting from target values derived from the requirements of the design problem or from design heuristics, desirability functions are used to relax these constraints and translate the design problem into a global model taking into account mathematical inferences (such as Eq. (4)) and desirability functions (Jeong \& Kim, 2009; Pasandideh \& Niaki, 2006; Sébastian, Quirante, Ho Kon Tiat, \& Ledoux, 2010).

Preference models are related to different types of knowledge ranging from analytical knowledge derived from physics or economics to design rules based on expertise or case-based reasoning (Mitra \& Basak, 2005; Saridakis \& Dentsoras, 2008). Every type of model may have a fair degree of accuracy and a comparable amount of prediction capability (Vernat, Nadeau, \& Sébastian 2010), however, they can be distinguished by their levels of subjectivity. This results in a major difficulty when combining different types of knowledge and their respective preference models (Scott \& Antonsson, 1998). Sanchis, Martinez, and Blasco (2008) and Zang, Friswell, and Mottershead (2005) have investigated the various methods used in engineering design to deal with this particular difficulty. Among these different approaches, preference aggregation methods (Dai, Scott, \& Mourelatos, 2004) are based on weighting processes of criteria and aggregation functions. They result in a unique preference indicator, which limits the complexity of the search space of the design problem and is used to select the proper trade-off between preferences before calculating a Pareto frontier. However, this approach requires the aggregation of preferences, whatever the nature of the knowledge intrinsic to the model. Consequently, subjective preferences such as, for instance, levels of confidence must be aggregated with others derived from simulation results based on physical analysis. Such a difficulty cannot be avoided since subjective preferences are inherent to design processes and the analysis of complex physical phenomena is essential to many design application domains.

Some authors propose to relate both types of knowledge by performing a dual process of selection/classification of solutions,

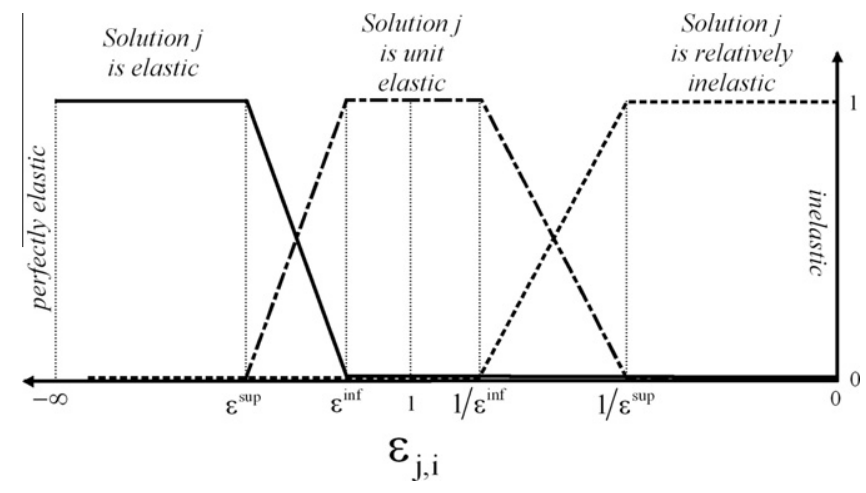

Fig. 4. Interpretation of elasticity quantities. 
which takes into account two different levels in the solution calculation. Subjective knowledge is used to sort solutions derived from a numerical investigation of the Pareto frontier of a design problem. Rather than optimizing a unique preference indicator, the optimization process merges a preference indicator and a dominance indicator. Molina, Santana, Hernandez Diaz, Coello, and Caballero (2009) uses a reference point in the design search space to define a dominance indicator relative to the observation variables $(Y)$ of design problem models. This approach relates to reference objectives (Wierzbicki, 1980) and, from a more general point of view, to Goal Programming methods (Martel \& Aouni, 1990; Tamiz, Jones, \& Romero, 1998).

\subsection{Modeling strategy profile}

In this paper, we propose to use arc-elasticity as a dominance indicator to select and rank design solutions. Fig. 5 summarizes the different classes of variables, functions and indicators used in the framework of this article. Generally speaking, preferences are computed from an indicator function inferred from a functional composition process. Indicator functions $\varphi$ are composed of three different functions:

$\varphi=\zeta \circ \delta \circ \mu$

These functions are:

- An observation function $(\mu)$, relating design variables to observation variables.

- An interpretation function $(\delta)$, relating observation variables to interpretation variables.

- An aggregation function $(\zeta)$, relating interpretation variables to a preference indicator.

From design variable vector $X$, observation variables $(Y)$ are computed through physical or economic models, interpreted $(Z)$ and aggregated into a first indicator $(v)$, which is called a performance indicator. At the same time, a second indicator $(u)$ is computed from the monitored design variable vector $(X)$ and from the design variables of a reference design solution $\left(X_{S}\right)$. Observation variables $\left(Y^{\prime}\right)$ are related to $X$ and $X_{s}$ through a criteria analysis procedure, interpreted $\left(Z^{\prime}\right)$ through a confidence assessment process and aggregated into the confidence indicator.

\subsection{Functions and knowledge}

Each of the interpretation and aggregation functions $(\mu, \delta, \zeta)$ are related to different types of knowledge ranging from objective information (such as models resulting from physical phenomena analysis) to subjective acquaintance (such as models resulting from confidence expression). Table 1 relates every preference deduction function to knowledge from which it originates in the scope of application of this paper.

The confidence observation and interpretation functions $\mu_{u}$ and $\delta_{u}$ stem from:

- The functional and technical analysis of the factors influencing the designers' confidence.

- The development of confidence functions based on risk assessments and analysis.

These confidence factors result in the identification of relevant variables taken into account in the confidence interpretation function. Expressing design rules is a complex topic (Brachman \& Levesque, 2004) linked to the field of knowledge engineering. Considerable scientific effort has been put into developing rulebased systems or translating engineering knowledge into rules through, for instance, fuzzy reasoning (Wong \& Lin, 1997). In this paper, our approach is illustrated through a single rule expressing designers' confidence in the technical feasibility of a solution. This unique rule is parameterized for each of the design variable $x_{i}$ of vector $X$ according to designers' knowledge in the context of the project. Confidence is related to one particular design situation where the designing process is initiated from a pre-existing design solution, regarded as reliable and experimented. From their subjective experience, these observation functions are based on the

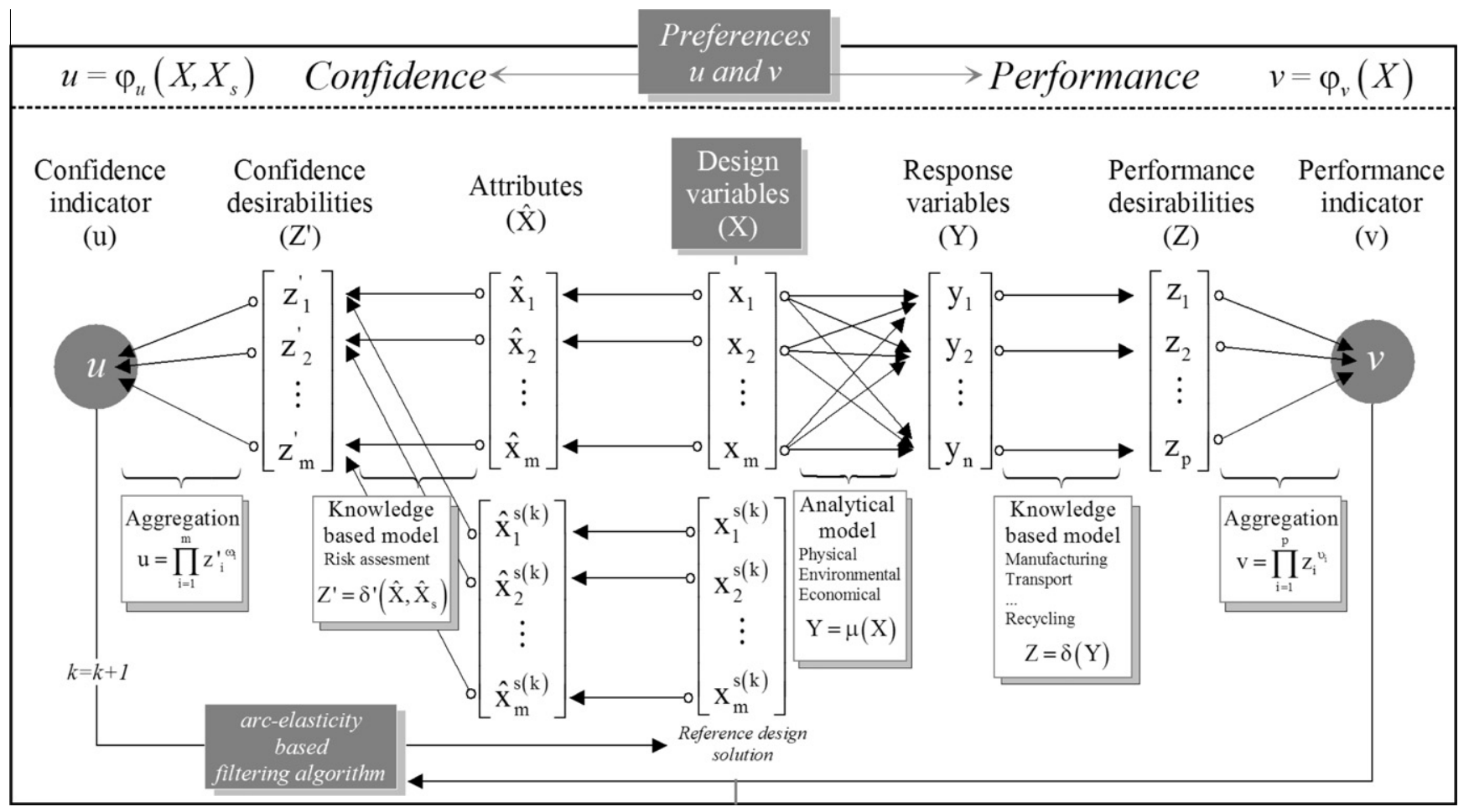

Fig. 5. Mapping of variables and inferences. 
Table 1

Connecting functions and knowledge.

\begin{tabular}{|c|c|c|c|c|c|}
\hline & Observation function $(\mu)$ & Interpretation function $(\delta)$ & $\begin{array}{l}\text { Aggregation } \\
\text { function }(\zeta)\end{array}$ & $\begin{array}{l}\text { Indicator function } \\
(\varphi)\end{array}$ & Preference \\
\hline Notation & $\mu_{v}$ & $\delta_{V}$ & $\zeta_{v}$ & & \\
\hline $\begin{array}{l}\text { Knowledge } \\
\text { setting }\end{array}$ & $\begin{array}{l}\text { Physics, economics, eco-environmental } \\
\text { analysis }\end{array}$ & $\begin{array}{l}\text { Design requirements supervising } \\
\text { heuristics }\end{array}$ & Strategic objectives & $\varphi_{v}=\zeta_{v} \circ \delta_{v} \circ \mu_{v}$ & $\begin{array}{l}\text { Performance } \\
v=\varphi_{v}(X)\end{array}$ \\
\hline Model & Analytical model & Harrington's desirability & $\begin{array}{l}\text { Derringer's } \\
\text { aggregation }\end{array}$ & & \\
\hline Parameterization & Physical, economical, E.-E. quantities & Target values and flexibility domains & $\begin{array}{l}\text { Weighting } \\
\text { parameters }\end{array}$ & & \\
\hline Notation & $\mu_{u}$ & $\delta_{U}$ & $\zeta_{u}$ & & \\
\hline $\begin{array}{l}\text { Knowledge } \\
\text { setting }\end{array}$ & Functional analysis, technical analysis & $\begin{array}{l}\text { Risk assessment and confidence } \\
\text { analysis }\end{array}$ & Strategic objectives & $\varphi_{u}=\zeta_{u} \circ \delta_{u} \circ \mu_{u}$ & $\begin{array}{l}\text { Confidence } \\
u=\varphi_{u}\left(X, X_{s}\right)\end{array}$ \\
\hline Model & Criteria definition & Design rules & $\begin{array}{l}\text { Derringer's } \\
\text { aggregation }\end{array}$ & & \\
\hline Parameterization & - & Functional parameters & $\begin{array}{l}\text { Weighting } \\
\text { parameters }\end{array}$ & & \\
\hline
\end{tabular}

relative distance $\left(\mu_{u}\right)$ between the design variables of the reference solution $X_{s}$ and candidate solution $X$. From the design variables of the pre-existing design configuration designers assess the feasibility of the modification of every design variable $\left(\delta_{u}\right)$.

This approach is motivated by the fact that many designing processes are based on one prior design configuration, which has been carried out, tested and validated. Designing processes are also learning processes where designers must take into account much significant information derived from previous projects; they refine their own expertise through the difficulties encountered in this global and recursive learning process. Physical processes and environments are related to many variability and uncertainty sources. In the course of this learning process, designers' confidence in the feasibility of design solutions evolves and goes through different stages. Designers use a step by step procedure to try and improve this prior solution by increasing its efficiency from a physical (energetic efficiency, mechanical stress, etc.), economic (investment or operative costs) or eco-environmental (eco-indicators) point of view. This improvement process tends to increase the distance between new and reference solutions. Designers are looking for an optimal compromise between carefulness and innovation.

The performance observation function $\mu_{v}$ results from complex analytical analysis of physical behavior and other scientific domains. It is implemented in simulation codes and combines models at several descriptive scales ranging from phenomenological scales to global balances of energy, momentum or costs. Interpretation function $\delta_{v}$ is based on the design requirements of the engineering design problem. Design requirements (Pahl \& Beitz, 1996) are defined through numerical values and flexibility levels of the expected performances of the system. Through interpretation functions, these requirements are used to translate the values of the observation variables into satisfaction or acceptability levels.

The aggregation functions $\zeta_{u}$ and $\zeta_{v}$ are used to balance the different objectives of the design process. Balancing is performed by adjusting the parameters of the aggregation functions according to the hierarchy of the design objectives. This hierarchy results in preference indicators $u$ and $v$ used to rank and select the most relevant design solutions.

\section{Observation, interpretation and aggregation}

\subsection{Observation functions}

The confidence indicator $u$ is built from the design variables of the problem. It is defined by assessing, for each of the design variables $x_{i}$, a relative distance criterion between the reference solution $X_{s}$ and the candidate solution $X$. Rather than using the design variables $x_{i}$ to define the relative distance criterion between the two solutions, it proves useful to employ an attribute $\hat{x}_{i}$ deduced from the design variable value. Attributes $\hat{x}_{i}$ are deduced from $x_{i}$ through a bijective function $\hat{x}_{i}\left(x_{i}\right)$. This attribute is a positive number selected because it is more representative of the gap between solutions than the design variables by themselves. For instance, let us consider, as in Section 5 , a system for which the design variables correspond to a number of heat exchangers placed in series or identification indexes of three components (heat exchangers, pumps or fans). In this case, we select the nominal powers of the heat exchangers, pumps and fans and the number of heat exchangers as being the attributes of the design variables. The nominal powers of heat exchangers in Watts per Kelvin and pumps or fans in Watts are regarded as suitable for ranking these devices through an ordinal order relation. On the contrary, the number of exchangers positioned in series is both the design variable and its corresponding attribute.

The observation function is defined from $\hat{x}_{i}$ of a candidate solution and $\hat{x}_{i}^{s}$ of the reference solution:

$\mu_{u}\left(x_{i}, x_{i}^{s}\right)=\frac{\hat{x}_{i}\left(x_{i}\right)-\hat{x}_{i}^{s}\left(x_{i}^{s}\right)}{\hat{x}_{i}\left(x_{i}\right)+\hat{x}_{i}^{s}\left(x_{i}^{s}\right)}$

It must be noted that $\mu_{u}$ is a real number ranging between 0 and 1 since the values of the attributes are constrained to be positive. The observation variables vector $Y^{\prime}$ is:

$Y^{\prime}=\left[\mu_{u}\left(x_{1}, x_{1}^{s}\right), \mu_{u}\left(x_{2}, x_{2}^{s}\right), \ldots, \mu_{u}\left(x_{m}, x_{m}^{s}\right)\right]^{T}$

\subsection{Performance interpretation function}

Response variables derived from the resolution of Eq. (4) are interpreted through desirability functions, a concept first introduced by Harrington (1965). Every response variable $y_{i}$ composing the vector $Y$ is related to a desirability value through one threshold function (see Fig. 6). Harrington's threshold functions for maximizing or minimizing response variables $y$ are:

$\delta_{v}(y)=\exp \left(-\exp \left(\beta_{v}+\alpha_{v} \cdot y\right)\right)$

with respective parameters of maximizing or minimizing threshold functions such as:

$$
\left\{\begin{array}{l}
\alpha_{v}=\frac{\ln \left(\ln \left(z^{-}\right) / \ln \left(z^{+}\right)\right)}{y^{+}-y^{-}} \\
\beta_{v}=\ln \left(-\ln \left(z^{-}\right)\right)-\alpha_{v} \cdot y^{+}
\end{array}\right.
$$

Desirability functions link response variables to preference levels, where zero value corresponds to minimal preference and 1 to maximal preference. One-sided functions require two limit specification parameters to be defined, namely, $y^{-}$and $y^{+}$. These limits correspond to desirability values close to one $(0.9)$ or zero $(0.1)$. They are related design requirements or objectives and bound satisfac- 


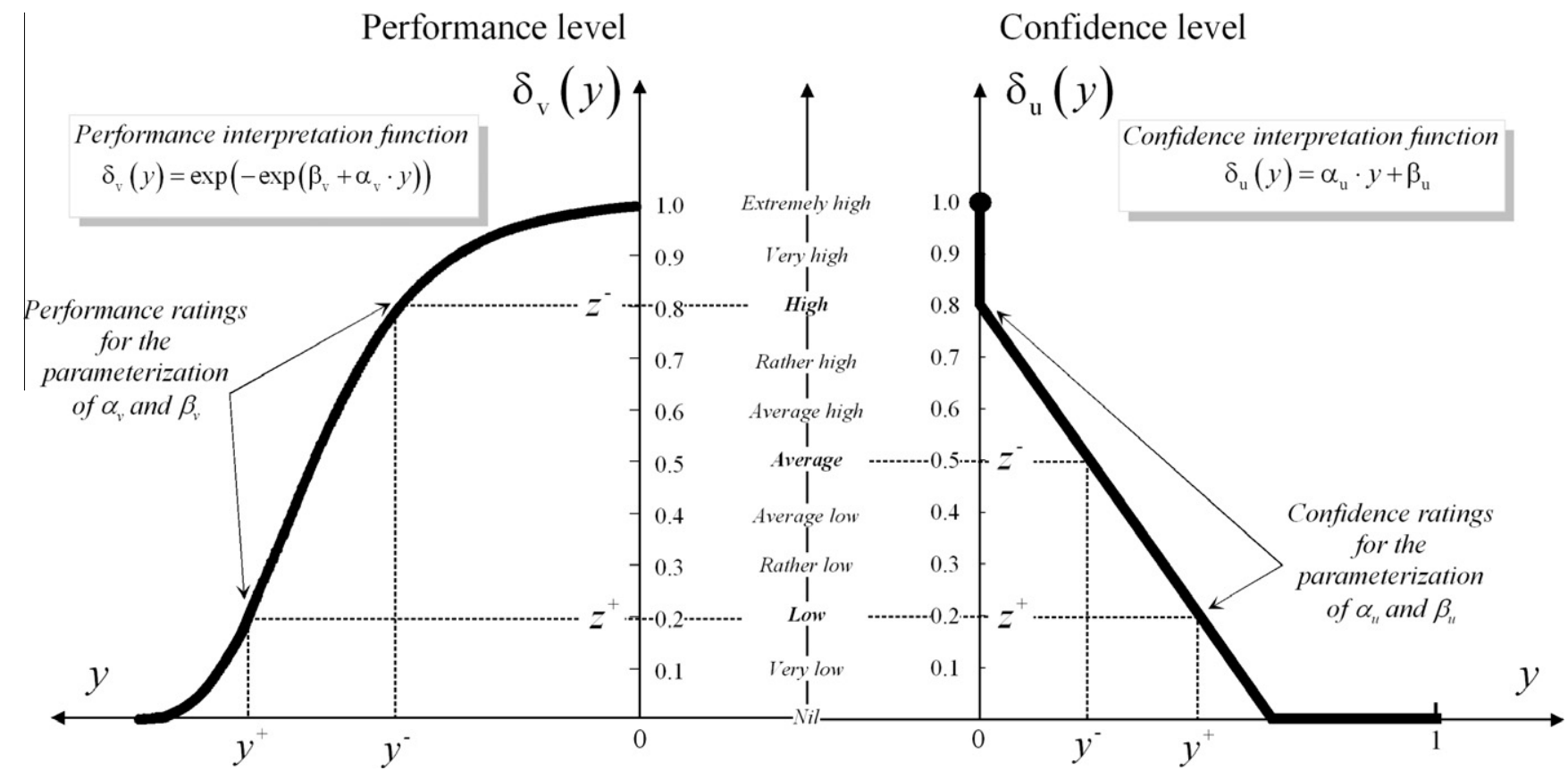

Fig. 6. Performance and confidence interpretation functions.

tory domains of values for every response variable. It must be noticed that, whereas one-sided Harrington's functions are used to express preferences on threshold values, Harrington also defined twosided functions, which are not presented here, to characterize preferences on closed value domains. Desirability values are assembled in vector $Z$, therefore:

$Z=\left[\delta_{v}\left(y_{1}\right), \delta_{v}\left(y_{2}\right), \ldots, \delta_{v}\left(y_{n}\right)\right]^{T}$

\subsection{Confidence interpretation function}

To illustrate our approach, a simple interpretation rule of designers' confidence in the feasibility of a design solution is proposed and presented in the right-hand part of Fig. 6. This rule assumes that the confidence of the designer:

- is a piecewise linear function,

- is not necessarily continuous in zero value of the $x$ axis and rates one on $y$-axis at this point,

- is bounded to range between zero and one on $x$-axis and $y$-axis.

The function is parameterized for every component of vector $Y^{\prime}$, by assessing its value on two different points. For each component $y_{i}^{\prime}$, this assessment is performed by determining two linguistic values (ranging from 'nil' to 'extremely high') and two numerical values (ranging between 0 and 1 ) of the observation variable $y_{i}^{\prime}$. From these values, the linguistic evaluations of confidence levels are related to two numerical value of the interpretation variable ranging between zero and one. Parameters $\alpha_{u}$ and $\beta_{u}$ of the interpretation function are calculated from these two points:

$\delta_{u}(y)=\alpha_{u} \cdot y+\beta_{u}$

with

$\left\{\begin{array}{lll}y=0, & \alpha_{u}, & \beta_{u}=1 \\ -\beta_{u} / \alpha_{u} \leqslant y \leqslant\left(1-\beta_{u}\right) / \alpha_{u}, & \alpha_{u}=\left(z^{+}-z^{-}\right) /\left(y^{+}-y^{-}\right) & \beta_{u}=z^{+}-\alpha_{u} \cdot y^{+} \\ y<-\beta_{u} / \alpha_{u}, & \alpha_{u}=0, & \beta_{u}=1 \\ y>\left(1-\beta_{u}\right) / \alpha_{u}, & \alpha_{u}=0, & \beta_{u}=0\end{array}\right.$
Desirability values are assembled in vector $Z^{\prime}$, therefore:

$Z^{\prime}=\left[\delta_{u}\left(y_{1}^{\prime}\right), \delta_{u}\left(y_{2}^{\prime}\right), \ldots, \delta_{u}\left(y_{m}^{\prime}\right)\right]^{T}$

\subsection{Aggregation of confidence and performance indicators}

The definition of the performance indicator results from the aggregation of the components of $Z$. In the following, we use an aggregation method based on the concept of desirability index introduced by Derringer (1994), Derringer and Suich (1980) and recently developed in multi-response optimization (Jeong \& Kim, 2009; Pasandideh \& Niaki, 2006). The main idea underlying Derringer's aggregation method is that any design becomes unacceptable as soon as at least one of the values of the performance variables is non-desirable. Starting from this principle, Derringer has proposed to aggregate individual desirability functions into a global desirability index through a weighted geometric mean:

$\zeta(Z)=\prod_{i=1}^{p}\left(z_{i}\right)^{v_{i}} \quad$ with $\quad \sum_{i=1}^{n} v_{i}=1$

where $v_{i}$ are weighting parameters, which may be derived from a sensitivity analysis (Sébastian et al., 2010).

The performance indicators resulting from Derringer's aggregation process are:

$\zeta_{u}=\zeta_{v}=\zeta, \quad u=\zeta\left(Z^{\prime}\right), \quad v=\zeta(Z)$

\subsection{Interpretation functions and arc-elasticity consistency}

It is important to highlight that the preference indicators $u$ and $v$ must be defined from similar scales of values to ensure the consistency of the design solution ranking process. In particular, this scaling constraint is imperative to guarantee that the arc elasticity concept can be used to select the most relevant design solutions from the values of $u$ and $v$. It is proposed to perform this scaling process through the interpretation functions $\delta_{u}$ and $\delta_{v}$. Fig. 7 illustrates this process based on pairwise comparisons of the desirability values using a linguistic interpretation scale. Every pair of 
desirability values of the interpretation functions are interpreted on the same linguistic scale ranging from "Null" to "Extremely high". In stages of development where designers' knowledge remains vague and somewhat ambiguous, interpretation modeling is mostly based on pairwise comparisons (Saaty, 2006) using linguistic values (Dong, $\mathrm{Xu}, \& \mathrm{Li}, 2008$ ). The strongest consistency is ensured by pairing interpretation values linked to a couple of observation variables through the linguistic interpretation scale. The scales of values are consistent if, for every interpretation function $\delta_{u}$ or $\delta_{v}$, every couple of interpretation values is consistent with the designers' linguistic interpretation. This consistency hypothesis is strong since the expression of designers' knowledge may be unclear. This difficulty can be overcome by using AHP techniques to determine the parameters of the desirability functions. Future developments of this work will also take into account the fuzziness of these parameters.

\section{Re-design of a geothermal air conditioning system}

\subsection{System presentation}

Considerable interest is currently focused on the development of innovative devices for low-power air-cooling of detached houses. The most traditional air conditioning technologies are calorific pumps using refrigerant compression. Due to the high investment costs and sizeable electrical energy consumption of these devices (usually ranging between 30 and $70 \mathrm{~W} / \mathrm{m}^{2}$, where square meters relate to the living area of the house), geothermal systems appear to be very good candidates for innovative developments in this area. Typical electrical energy consumption by geothermal cooling systems ranges between 1 and $2 \mathrm{~W} / \mathrm{m}^{2}$. However, thermal conductivity of soils is generally low (around $2 \mathrm{~W} / \mathrm{mK}$ ), which highly constrains the overall dimensions of the thermal exchangers harnessing the calorific energy from the ground. Consequently, some geothermal cooling systems are dimensioned to improve the average thermal comfort of houses, rather than meeting the requirements of maintaining low temperatures inside the house during unusual heat wave episodes.

Some promising developments of geothermal air conditioning systems tend toward low power but energetically efficient systems. The typical cooling powers of the air conditioning devices discussed in this paper range between 300 and $500 \mathrm{~W}$ for a $100 \mathrm{~m}^{2}$ single-family house, which is low compared to calorific pumps generating several kilowatts of cooling power. It may be argued against calorific pumps that, generally, they are under-utilized in temperate climate areas despite their high investment costs. For several reasons, most heat pump customers are reluctant to make use of a system that consumes a lot of energy during long periods of time. For detached houses and in a context of sustainable development, air cooling systems based on refrigerant compression are regarded as luxury products by significant population brackets. Geothermal systems, on the contrary, are regarded as cheap, eco-friendly and efficient for most periods of time.

In such an evolutionary context, both difficult to predict and yet promising, small- and medium-sized companies are trying to develop this equipment and put it into practice. Designing geothermal air conditioning systems is faced with the need for technological innovation and risk limitation. The application presented in this article has been carried out by a small enterprise specialized in designing

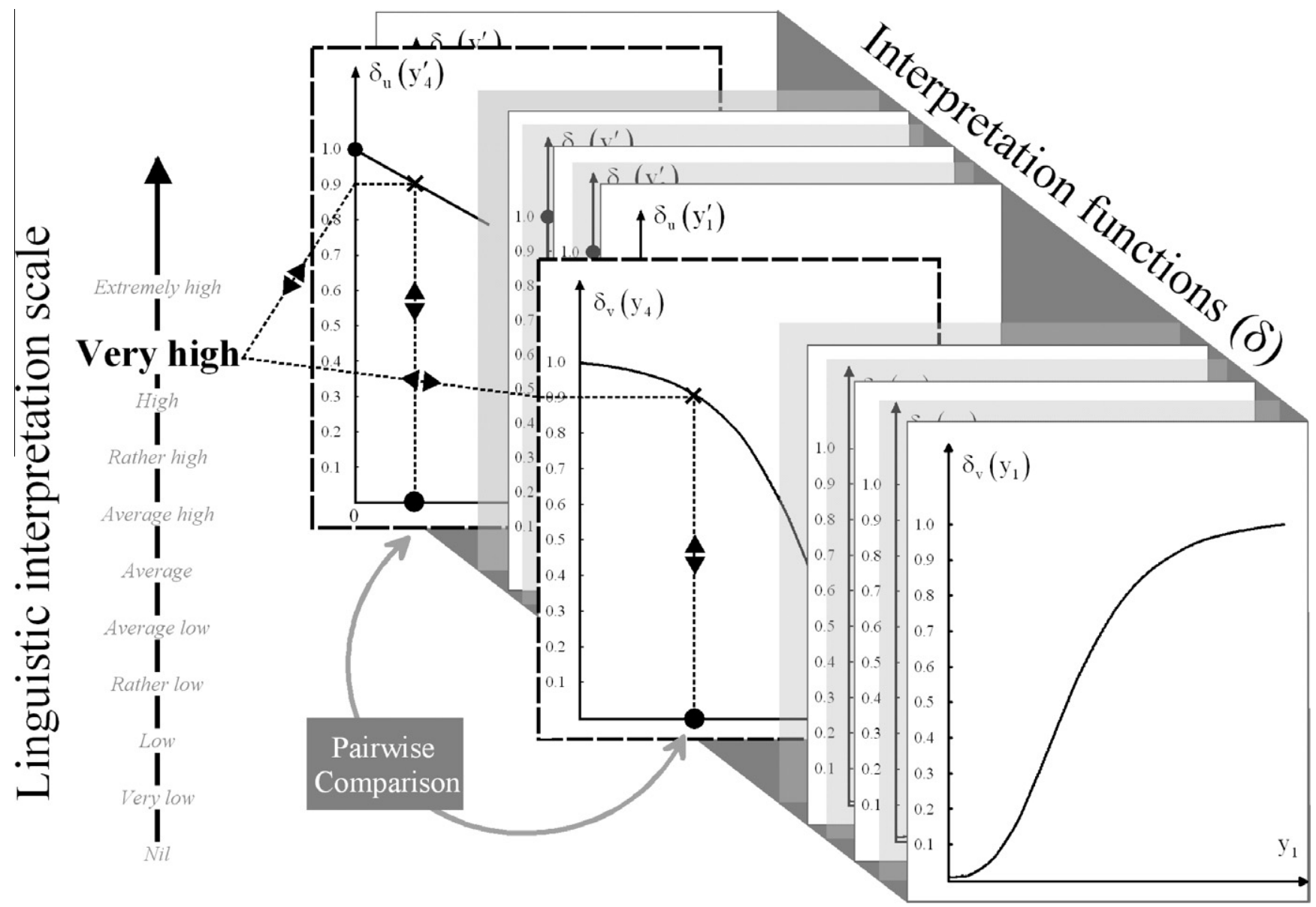

Fig. 7. Pairwise comparisons of interpretation functions. 
(from assembled equipments), assembling and installing energy systems. The company's activity in the field of geothermal systems concerns small equipment, for which they excavate and prepare the ground and also assemble and install the system inside the house.

\subsection{Design diagnosis and problem modeling}

Geothermal systems are built from three main functional units (see Fig. 8) and the objectives are: (i) harnessing cold calorific energy from the ground, (ii) conditioning the temperature of some atmospheric air with this calorific energy along with its velocity using electrical energy, and then (iii) distributing the air inside the house. The company has identified one particular difficulty in the design of their equipment relating to the compactness of the air/antifreeze solution heat exchanger in the air conditioning unit. In single-family houses, there is often little available space in the utility room, which highly constrains the overall dimensions (height and width) of the casing for the exchanger. Another difficulty, regarded as secondary compared to the space encumbrance problem, concerns the temperature variation in the air flowing through the heat exchanger. The efficiency of the exchanger is low (about $40 \%$ ) but has been maximized from supplier catalogues.

Starting from basic dimensional data and fluid flow rates, it was quickly realised that the efficiency of the exchanger could be significantly increased and, at the same time, that the overall dimensions of the exchanger could be decreased. The difficulty the company had in designing the air conditioning system was mainly due to the type of exchanger used for cooling the atmospheric air. These exchangers are made of a copper tube circulating inside a bundle of approximately one millimeter spaced aluminum plates. Most of these exchangers are used for air conditioning applications based on refrigerant compression. They were originally designed to achieve an optimal compromise between maximizing the energy transferred by the fluid circulating inside the tube (rather than maximizing/minimizing the temperature of the air circulating outside the tube) and minimizing the volumes and costs of the exchanger. This choice is inherent in the functioning of calorific pumps since, outside the house, atmospheric air is used as an external environment to evacuate the calorific energy, whereas inside the house, air is cooled through a recirculation process. Regarding the air-flow circuit inside the exchanger, the air path is short (50 $\mathrm{mm}$ in Fig. 8) and consequently the air cooling effectiveness of these exchangers is usually close to $40 \%$ around their nominal operating point. These exchangers are not intrinsically suitable for maximum air cooling effectiveness.

This first analysis was carried out by taking on-site experimental measurements of the air temperatures inside the conditioning unit. Temperature measurements showed that, due to the low efficiency of the fan moving air through the circuit, a significant proportion (approximately 70\%) of the air's kinetic energy was degraded in calorific energy inside the fan and air temperature increased about two degrees Celsius. In the same manner, it was difficult to assess the relevance of the choice of liquid pump, and the design of the conditioning unit must be regarded as a global interaction process between the pump, fan and heat exchanger. Based on these diagnoses and experimental observations, a model $\left(\mu_{u}\right)$ was developed taking into account physical phenomena, purchase prices or energy consumption costs in the conditioning unit; this model aimed at observing the performance of several thousands of different combinations of pumps, fans and heat exchangers selected from component supplier catalogues. Because the air path inside a single heat exchanger is short (resulting in low air cooling efficiency), several heat exchangers can be placed in series along the air-flow circuit inside the same casing to increase exchange efficiency. The exchangers are connected together in a counter-current circuit using curved copper tubes.

The model contains four different design variables $(X)$ corresponding to three identification indexes for the fan, pump and heat exchanger $\left(x_{1}, x_{2}\right.$ and $\left.x_{3}\right)$, along with the number of exchangers in series $\left(x_{4}\right)$. It also contains five different observation variables $(Y)$ which are:

- The operational cost of the system $\left(\mathrm{y}_{1}\right)$ derived from the purchase prices and electrical energy consumption costs of the conditioning unit components.

- The compactness indicator $\left(\mathrm{y}_{2}\right)$ derived from the characteristic dimension (height or width) of the space encumbrance of the heat exchanger case.

- The system energetic Coefficient of Performances $\left(\mathrm{y}_{3}\right)$, i.e. the ratio between the cooling power efficiency and the electrical power consumption.

- The temperature of the air at the distributing unit outlet $\left(\mathrm{y}_{4}\right)$.

- The volume flow rate of the air at the distributing unit outlet $\left(\mathrm{y}_{5}\right)$.

The model $\mu_{u}$ is based on one-dimensional balances of calorific energy and pressure along the air and liquid circuits (inside the ground exchanger). It must be noted that:

- The friction factors and heat transfer coefficients of the air inside the tube and fin exchangers are based on Gray and Webb's model (Gray \& Webb, 1986) and corroborated from data provided by the company that manufactures the exchangers.

- The global calorific energy balance inside the heat exchangers is derived from a counter current Number of Transfer Unit model (Rohsenow, Hartnett, \& Cho, 1998).

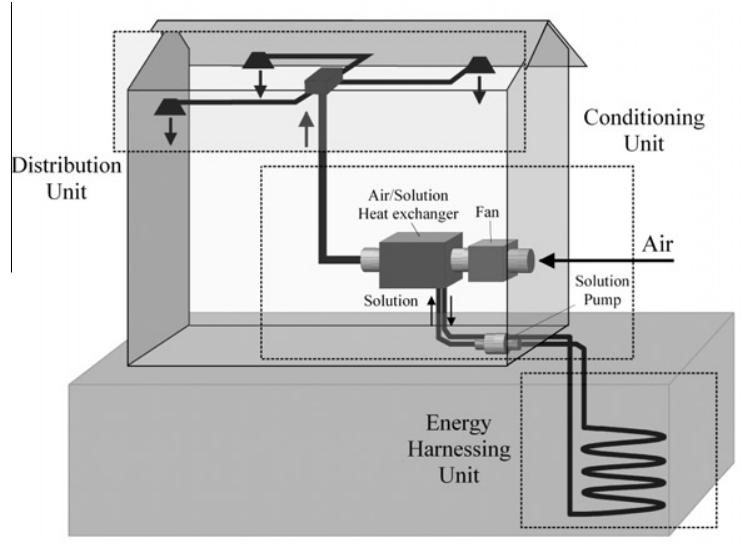

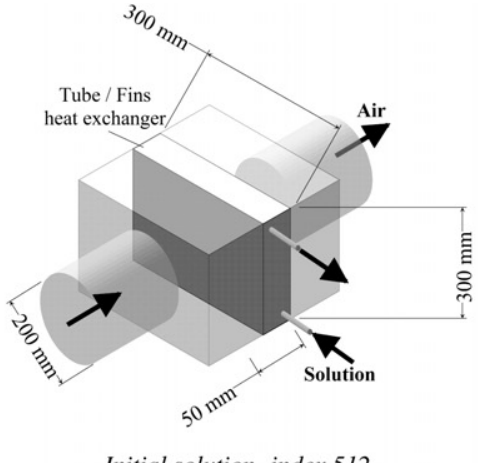

Initial solution -index 512-

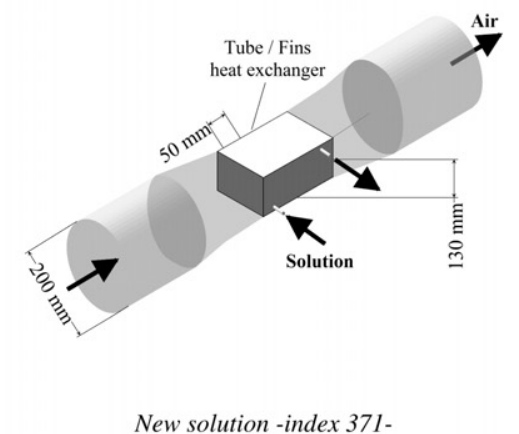

New solution -index 371 -

Air/Liquid heat exchanger

Fig. 8. Geothermal air conditioning system. 
- The characteristic functions (pressure vs. flow rate) of the fans and pumps have been interpolated from supplier catalogues.

- The equipment refers to supplier non-negotiated costs and energy costs refer to the most usual contractual prices in France.

In the context of small enterprises specialized in designing, manufacturing, assembling or installing energetic systems, such a model, on its own, is inadequate to support decision making. Designers' reasoning is greatly constrained by risks or uncertainties as much as the need for innovation relating to their products. Decisions are made in a bounded rationality context since any transformation in the geothermal system configuration would result in new questionings and decision requirements beyond the scope of the present model. In particular, designing from assembled parts like fans, ducts, etc. entails co-dependent relationships between companies, which may affect the feasibility of design solutions whatever their performance levels. The implementation of competitive solutions may be delayed or canceled due to practical infeasibility or lack of confidence in the feasibility of solutions.

Confidence observation and interpretation functions are based on designers' concerns about the presumed accessibility of parts or components and the difficulty in assembling them. Parts or components already present and available in suppliers' catalogues are regarded as highly accessible (high confidence), whereas non-standard components such as multiple heat exchangers assembled in series in a single case are regarded as moderately accessible (average confidence). The left part of Fig. 9 shows the interpretation functions used to express the confidence levels as a function of four observation variables $\left(y_{1}^{\prime}\right.$ to $\left.y_{4}^{\prime}\right)$. Values of $y^{\prime}$ equal to zero correspond to the existing design configuration and, consequently, are related to a confidence value of one. Making an adjustment, even a small one, to one of the observation variables results in a degradation of its respective confidence level; this degradation is low for the variables $y_{1}^{\prime}$ to $y_{3}^{\prime}$ (extremely high to very high) and more significant for the variable $y_{4}^{\prime}$ (extremely high to average). More to the point, making an adjustment (relative to the existing design configuration) to some overall characteristics of components, such as the dimensions of fans and pumps, affects the physical environment of the initial system; this leads to necessary adaptations of the conduits and connection components, the consequences of which are difficult to predict in the early stages of design processes. Therefore, the interpretation functions of confidence decrease while the non-dimensional deviations increase from zero to one; since adaptations are regarded as low, interpretation functions only decrease from 0.9 to 0.8 or from 0.5 to 0.4 . Thus, $\delta_{u}$ is defined from:

$$
\left\{\begin{array} { l } 
{ y _ { 1 } ^ { - } = y _ { 2 } ^ { - } = y _ { 3 } ^ { - } = y _ { 4 } ^ { - } = 0 ^ { + } } \\
{ z _ { 1 } ^ { - } = z _ { 2 } ^ { - } = z _ { 3 } ^ { - } = 0 . 9 } \\
{ z _ { 4 } ^ { - } = 0 . 5 }
\end{array} \text { and } \left\{\begin{array}{l}
y_{1}^{+}=y_{2}^{+}=y_{3}^{+}=y_{4}^{+}=1 \\
z_{1}^{+}=z_{2}^{+}=z_{3}^{+}=0.8 \\
z_{4}^{+}=0.4
\end{array}\right.\right.
$$

The right-hand part of Fig. 9 shows the Harrington's interpretation function related to the temperature of the air at the conditioning system outlet. Similar functions have been defined for every term of $\mathrm{Y}$ and the parameters defining $\delta_{v}$ are:

- Relative operating cost: $y_{1}^{-}=100 \%, z_{1}^{-}=0.9, y_{1}^{+}=200 \%$, $z_{1}^{+}=0.1$.

- Space encumbrance: $y_{2}^{-}=0.15 m, z_{2}^{-}=0.9, y_{2}^{+}=0.3 m, z_{2}^{+}=0.1$.

- Air cooling: $y_{3}^{-}=6.5^{\circ} \mathrm{C}, z_{3}^{-}=0.1, y_{3}^{+}=10^{\circ} \mathrm{C}, z_{3}^{+}=0.9$.

- Air renewal time: $y_{4}^{-}=1 \mathrm{~h} 12 \mathrm{~min}, z_{4}^{-}=0.9, y_{4}^{+}=1 \mathrm{~h} 45 \mathrm{~min}$, $z_{4}^{+}=0.1$.

- Energetic performance (COP): $y_{5}^{-}=4, z_{5}^{-}=0.1, y_{5}^{+}=10$, $z_{5}^{+}=0.9$.
For the sake of simplicity, the parameterization process of the aggregation functions will not be justified and detailed in this paper. In the following, we use:

$\zeta\left(Z^{\prime}\right)=z_{1}^{\prime 0.2} \cdot z_{2}^{\prime 0.4} \cdot z_{3}^{\prime 0.2} \cdot z_{4}^{\prime 0.2}$

$\zeta(Z)=z_{1}^{0.1} \cdot z_{2}^{0.25} \cdot z_{3}^{0.2} \cdot z_{4}^{0.25} \cdot z_{5}^{0.2}$

\subsection{Results and discussion}

From these performance and confidence models, each of the 750 candidate solutions of a solution set derived from a list of 5 fans, 10 liquid pumps and 3 heat exchangers (from 1 to 5 heat exchangers positioned in series) was simulated. Fig. 10 shows the confidence and performance indicators related to these 750 design configurations. In this list, solution index 512 corresponds to the design configuration currently developed by the company. Height Pareto-dominant solutions and, among them, four arc-elastic dominant solutions (including solution 512) arise from numerical computations. Fig. 10 mainly highlights two clusters of solutions. On the right of the figure, a first set of solutions corresponds to designs related to one single heat exchanger and, consequently, to high confidence indicator values since the initial reference solution also includes one exchanger. On the left of the figure, the second cluster of solutions corresponds to design solutions with multiple heat exchangers (from 2 to 5 exchangers). These solutions degrade the values of the confidence indicator; however some of them appear to increase the performance indicator considerably.

Solution 262 is very close to the initial solution from the confidence point of view. Despite the relatively low performances of this solution, it emerges from the arc elasticity maximization algorithm as being the first to take the system re-design process into consideration. Table 2 presents the values of vectors $X$ and $Y$ corresponding to the arc-elastic dominant solutions. This table shows that, starting from solution 512 , solution 262 is built by replacing exchanger number 3 (dimensions in millimeters $320 \times 320 \times 50$ ) by exchanger number 2 (dimensions in millimeters $250 \times 250 \times 50$ ). As exchanger 2 is smaller than exchanger 3 , this alternative drastically improves the system performances relating to space encumbrance and, to a lesser extent, decreases the cost of the system. This new exchanger has a smaller exchange surface than the previous one, which should result in a degradation of the air cooling. However, the decrease in air cooling proves to be very low because the air velocity in the initial configuration is very low (about $0.5 \mathrm{~m} /$ s) and most of the exchange surface is under-utilized. It must be noticed that, initially, space encumbrance was the main concern of the designers of the geothermal system. From a very simple transformation of the existing system this difficulty can be solved, whereas, from the point of view of an expert in the physical behavior of heat exchangers, this solution seems not particularly effective. By combining subjective and objective points of view and taking into account design process constraints related to lack of information or cognitive limitations, this approach can explain designers' preferences in some particular contexts. Faced with specific difficulties, designers may prefer a sub-optimal design solution when their understanding leans towards experimented design configurations that inspire their confidence. In a bounded rationality context, decision-makers may prefer solutions related to maximal levels of confidence to solutions related to maximal levels of performance.

Solutions 322 and 371 increase the thermal power of the system from 350 to 640 Watts by using several heat exchangers of type number 2 positioned in series and a more powerful fan, which jointly increase the thermal transfer surface and discharge velocity of the air flowing inside the heat exchangers. The air renewal time decreases from about $1 \mathrm{~h} 45 \mathrm{~min}$ to $1 \mathrm{~h} 30 \mathrm{~min}$ improving ventilation in the house, while the air cooling increases from 5.2 to $8.3^{\circ} \mathrm{C}$. 

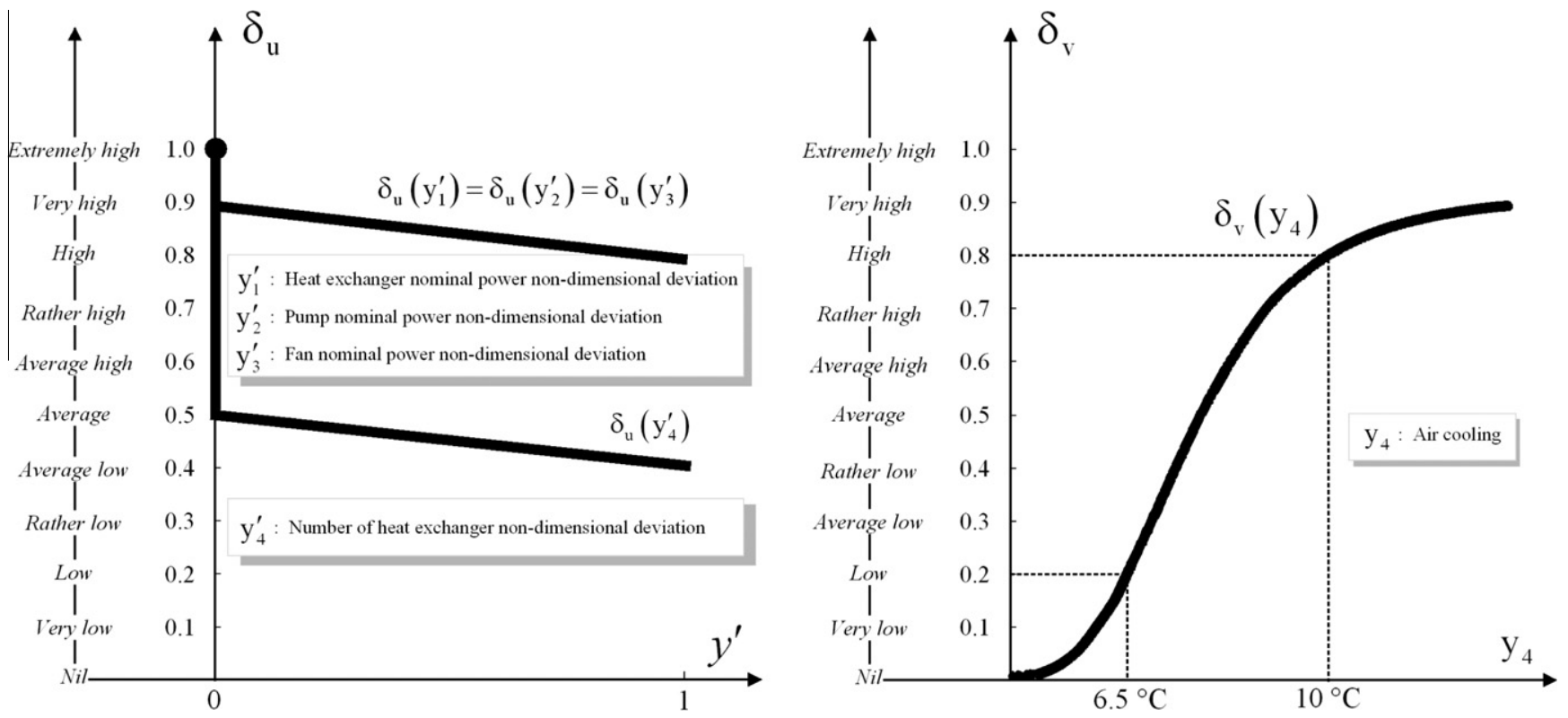

Fig. 9. Confidence interpretation functions (left) and fourth performance interpretation function (right).

These two solutions significantly improve the thermal comfort provided by the system, however, they also increase its operative cost. The filtering algorithm based on elasticity optimization allows screening half of the Pareto-efficient solutions. By sorting solutions according to their confidence levels (descending order) and performance levels (ascending order), the algorithm simulates a decision-making process in which designers jump from one solution to another by increasing the risk level inherent in their decisions.

\section{Conclusion and prospects}

Design processes are constrained by the need for performance improvement (or even innovation) and failure risk limitation of industrial products. This paper introduces and investigates the concept of performance/confidence arc-elasticity in mechanical design. Arc-elasticity has been defined as a ratio of two nondimensional preference indicators. Preference is defined in terms of distance between an initial solution and candidate solutions; it tends to limit the transformations of the initial solution since transforming well-controlled solutions tends to increase the epistemic uncertainties in the design process. From the concept of elasticity, an optimal solution screening methodology has been proposed. This approach aims at selecting design candidate solutions according to their arc-elasticity, which is relative to other solutions. Valuable solutions maximize the performances of the mechanical system and minimize the epistemic uncertainties arising from the complexity of the physical, economical and technical environment of the system.

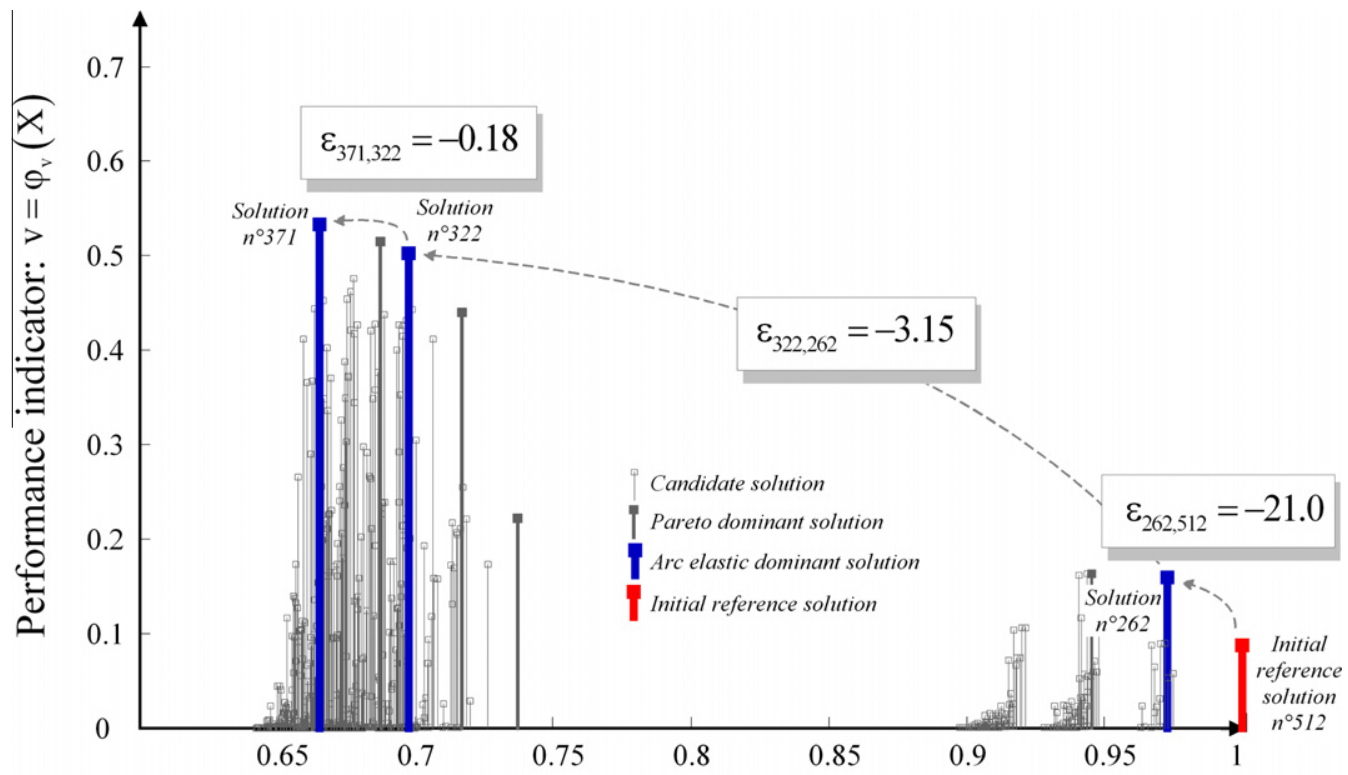

Confidence indicator: $\mathrm{u}=\varphi_{\mathrm{u}}\left(\mathrm{X}, \mathrm{X}_{512}\right)$

Fig. 10. Performance and confidence levels of the design solutions (among 750 alternatives). 


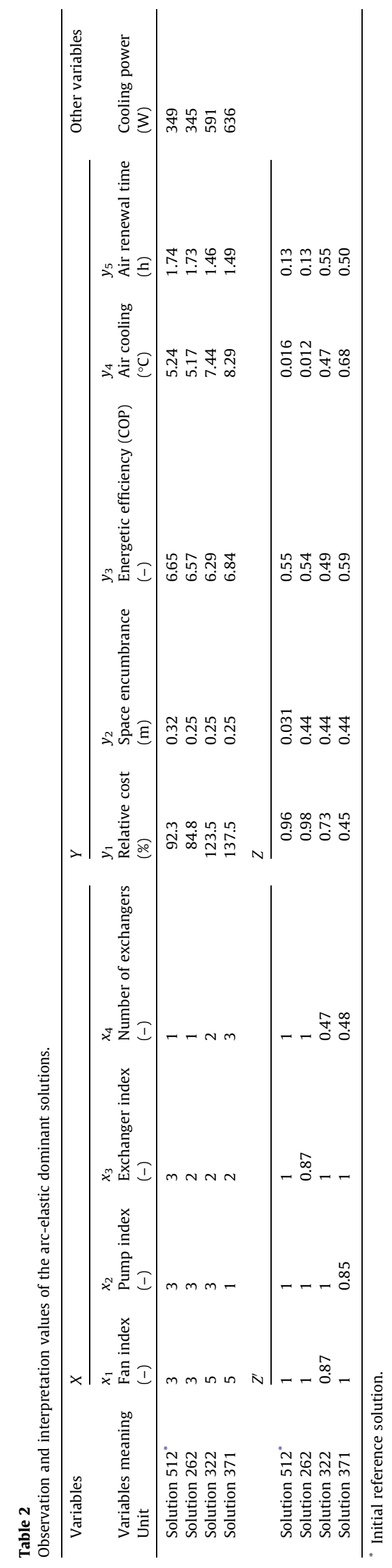

The main bottleneck in this approach derives from the consistency requirement for the scales of the interpretation functions. At the current stage of development of this work, consistency is ensured by assuming that designers are able to define interpretation scales through a unique linguistic interpretation scale without ambiguities. Future developments will take into account the fuzziness of designers' knowledge using fuzzy logic techniques. Thus the definition parameters of the interpretation functions will be fuzzy quantities.

This article focuses on a particular modeling method of performance and confidence indicators. However, our future developments are concerned with more general definitions of these indicators. In particular, preference has been considered as prior information resulting from the investigation of pre-existing systems observable through their design variables. Design variable values of pre-existing systems are used to guide designers' decisions by restricting the transformation of the initial configuration. However, preference may also concern more valuable expertise resulting from knowledge contained in the design models. Design heuristics derived from analytical and experimental knowledge are based on the observation of physical orders of magnitude and may be used to define other levels of preference. For instance, heat exchanger dimensioning and design can be guided by the simultaneous observation of some variables such as the exchanger compactness, heat transfer coefficients, fluid velocities, heat capacity ratios and thermal efficiency. From the order of magnitude of these variables, designers may derive confidence levels on the model's validity, which may contribute to the definition of preference functions. New developments of the methodology presented in this paper are also interested in this type of application.

\section{References}

Antonsson, E. K., \& Sebastian, H.-J. (2005). Fuzzy fitness functions applied to engineering design problems. European Journal of Operational Research, 166, 794-811.

Augusto, O. B., Rabeau, S., Dépincé, P., \& Bennis, F. (2006). Multi-objective genetic algorithms: A way to improve the convergence rate. Engineering Applications of Artificial Intelligence, 19, 501-510.

Bantayan, N. C., \& Bishop, I. (1998). Linking objective and subjective modelling for land use decision making. Landscape and Urban Planning, 43, 35-48.

Ben-Haim, Y. (2000). Robust rationality and decisions under severe uncertainty. Journal of the Franklin Institute, 337, 171-199.

Berliner, C., \& Brimson, J. (1988). Cost management for today's advanced manufacturing. Boston: Harvard Business Press.

Beuthe, M., Jourquin, B., Geerts, J.-F., \& Koul à Ndjang'Ha, C. (2001). Freight transportation demand elasticities: A geographic multimodal transportation network analysis. Transportation Research Part E, 37, 253-266.

Brachman, R. J., \& Levesque, H. J. (2004). Knowledge representation and reasoning. 978-1-55860-932-7. Amsterdam: Elsevier/Morgan Kaufmann, p. 381.

Collignan, A., Sébastian, P., Pailhès, J., \& Ledoux, Y. (2011). Qualification of solutions in mechanical design through the concept of elasticity. Research in interactive design. 978-2-8178-0168-1. Springer-Verlag, p. 146.

Cournot, A. (1838). Recherches sur les Principes Mathématiques de la Théorie des Richesses. Paris: Hachette.

Dai, Z., Scott, M. J., \& Mourelatos, Z. P. (2004). Improving robust design with preference aggregation methods. SAE Transactions, 113, 536-550.

Derringer, G. (1994). A balancing act: Optimizing a product's properties. Quality Progress, 51-58.

Derringer, G., \& Suich, R. (1980). Simultaneous optimization of several response variables. Journal of Quality Technology, 12, 214-219.

Dong, Y., Xu, Y., \& Li, H. (2008). On consistency measures of linguistic preference relation. European Journal of Operational Research, 189, 430-444.

Drèze, X., \& Zufryden, F. (2004). Measurement of online visibility and its impact on Internet traffic. Journal of Interactive Marketing, 18, 20-37.

Gray, D. L., \& Webb, R. L. (1986). Heat transfer and friction correlations for plate fin and tube heat exchangers having plain fins. In Proceedings of the eighth international heat transfer conference (Vol. 6, pp. 2745-2750).

Greco, S., Matarazzo, B., \& Słowiński, R. (2001). Rough sets theory for multicriteria decision analysis. European Journal of Operational Research, 129, 1-47.

Harrington, E. C. (1965). The desirability function. Industrial Quality Control, 21, 494-498.

Hung, K.-C., Julian, P., Chien, T., \& Jin, W. T.-H. (2010). A decision support system for engineering design based on an enhanced fuzzy MCDM approach. Expert Systems with Applications, 37, 202-213. 
Jeong, I.-J., \& Kim, K.-J. (2009). An interactive desirability function method to multiresponse optimization. European Journal of Operational Research, 195, $412-426$.

Marshall, A. (1920). Principles of economics. London: Macmillan and Co., Ltd.

Martel, J. M., \& Aouni, B. (1990). Incorporating the decision-maker's preferences in the goal-programming model. Journal of Operational Research Society, 41, 1121-1132.

Mitra, R., \& Basak, J. (2005). Methods of case adaptation: A survey. International Journal of Intelligent Systems, 20, 627-645.

Molina, J., Santana, L. V., Hernandez Diaz, A. G., Coello, C. A., \& Caballero, R. (2009). g-Dominance: Reference point based dominance for multiobjective metaheuristics. European Journal of Operational Research, 197, 685-692.

Nepal, B., Yadav, O. P., \& Murat, A. (2010). A fuzzy-AHP approach to prioritization of CS attributes in target planning for automotive product development. Expert Systems with Applications, 37, 6775-6786.

Odeck, J., \& Brathen, S. (2008). Travel demand elasticities and users attitudes: A case study of Norwegian toll projects. Transportation Research Part A, 42, 77-94.

Pahl, G., \& Beitz, W. (1996). Engineering design: A systematic approach. Berlin: Springer-Verlag.

Pasandideh, S. H. T., \& Niaki, S. T. A. (2006). Multi-response simulation optimization using genetic algorithm within desirability function framework. Applied Mathematics and Computation, 175, 366-382.

Perny, P. (1998). Multicriteria filtering methods based on concordance and nondiscordance principles. Annals of Operations Research, 80, 137-165.

Rohsenow, W., Hartnett, J., \& Cho, Y. (1998). Handbook of heat transfer. McGraw-Hill Professional Publishing.

Saaty, T. L. (2001). Fundamentals of decision making and priority theory. AHP series (Vol. 6). 0-9620317-6-3. RWS Publications, p. 478.

Saaty, T. L. (2006). Rank from comparisons and from ratings in the analytic hierarchy/network processes. European Journal of Operational Research, 168, 557-570.
Sanchis, J., Martinez, M. A., \& Blasco, X. (2008). Integrated multiobjective optimization and a priori preferences using genetic algorithms. Information Sciences, 178, 931-951.

Saridakis, K. M., \& Dentsoras, A. J. (2008). Soft computing in engineering design - A review. Advanced Engineering Informatics, 22, 202-221.

Scott, M. J., \& Antonsson, E. K. (1998). Aggregation functions for engineering design trade-offs. Fuzzy Sets and Systems, 99, 253-264.

Sébastian, P., Quirante, T., Ho Kon Tiat, V., \& Ledoux, Y. (2010). Multi-objective optimization of the design of two-stage flash evaporators: Part 2. Multiobjective optimization. International Journal of Thermal Sciences, 49(2), 2459-2466.

Simon, H. A. (1982). Models of bounded rationality (Vol. 2). Cambridge, MA: MIT Press, pp. 209-238.

Tamiz, M., Jones, D., \& Romero, C. (1998). Goal programming for decision making An overview of the current state-of-the-art. European Journal of Operational Research, 111, 569-581.

Vernat, Y., Nadeau, J. P., \& Sébastian, P. (2010). Formalisation and qualification of models adapted to preliminary design. International Journal on Interactive Design and Manufacturing, 4(1), 11-24.

Wang, J. R. (2001). Ranking engineering design concepts using a fuzzy outranking preference model. Fuzzy Sets and Systems, 119, 161-170.

Wierzbicki, A. P. (1980). The use of reference objectives in multiobjective optimization. In Multiple criteria decision making theory and application (pp. 469-486). New York: Springer-Verlag.

Wong, C. C., \& Lin, N. S. (1997). Rule extraction for fuzzy modelling. Fuzzy Sets and Systems, 88, 23-30.

Zang, C., Friswell, M. I., \& Mottershead, J. E. (2005). A review of robust optimal design and its application in dynamics. Computers \& Structures, 83, 315-326. 